\title{
Recurrent Centroblastic Lymphoma
}

National Cancer Institute

\section{Source}

National Cancer Institute. Recurrent Centroblastic Lymphoma. NCI Thesaurus. Code C8926.

The reemergence of centroblastic lymphoma after a period of remission. 